\title{
Teacher education ICT appropriation model TEAM: A model for ICT appropriation in early childhood initial teacher education
}

\section{Rosina Merry}

\begin{abstract}
Early childhood initial teacher education programmes are only beginning to use information and communication technology (ICT) as part of their curriculum. There is limited research or practice knowledge about how student teachers learn to use ICT for pedagogical purposes. This doctoral study investigated how student teachers might be supported to appropriate and integrate ICT into their developing teaching practice. The study endeavours to understand the experiences of student teachers and practising early childhood teachers. The 230 student teachers in the study were from one university in New Zealand that offers early childhood initial teacher education (ITE).
\end{abstract}

The study utilised interpretative, qualitative methodology. Data were collected over two years with two cohorts of student teachers who were engaged in online discussions in the course of their ITE studies. Thirty-three practising early childhood teachers participated in semi-structured interviews. The online discussions and the interviews provided the material for analysis. Analysis took the form of thematic analysis.

The key outcome from this study is the development of the Teacher Education ICT Appropriation Model (TEAM). This is a theoretical model for what is needed to support student teacher and teacher use of ICT. The model is underpinned by a sociocultural view of learning and acknowledges and responds to the social nature of teaching and learning. The model includes key elements - subjective norms, relational trust, ICT cultural tools and enjoyment-as central to creating a sociocultural pedagogical place and space for ICT use. It also takes into account the influence of policy, curriculum and assessment on teaching and learning. Findings indicate these elements are all interrelated in the successful development of effective pedagogy.

The thesis argues that, when curriculum takes a sociocultural perspective on learning, ITE must do so as well. This means that, where ITE includes introducing tertiary students to teaching with and through ICT, sociocultural elements must be taken into account and frame up ITE. This thesis sets out just such a frame.

Wilf Malcolm Institute of Educational Research, Faculty of Education, University of Waikato, Hamilton, New Zealand ISSN: 2382-0373

Permanent Research Commons link to full thesis: http://hdl.handle.net/10289/10844

(p. 115) 